\section{(2) OPEN ACCESS}

\title{
The good, the bad and the ugly: pandemic priority decisions and triage
}

\author{
Hans Flaatten, ${ }^{1,2}$ Vernon Van Heerden, ${ }^{3}$ Christian Jung, ${ }^{4}$ Michael Beill, ${ }^{3}$ \\ Susannah Leaver, ${ }^{5}$ Andrew Rhodes, ${ }^{6}$ Bertrand Guidet, ${ }^{7}$ Dylan W deLange ${ }^{8}$
}

\begin{abstract}
${ }^{1}$ Department of Anaesthesia, Haukeland Universitetssjukehus, Bergen, Norway

${ }^{2}$ Intensive Care and Department of Clinical Medicine, Haukeland Universitetssjukehus, Bergen, Norway

${ }^{3}$ General Intensive Care Unit, Hadassah Medical Center, Jerusalem, Jerusalem, Israel ${ }^{4}$ Division of Cardiology, Pulmonology and Vascular Medicine, Heinrich-HeineUniversity, Düsseldorf, Germany ${ }^{5}$ Intensive Care and Respiratory Medicine, St George's University Hospitals NHS Foundation Trust, London, UK

${ }^{6}$ St George's University Hospitals NHS Foundation Trust, London, UK

${ }^{7}$ Assistance Publique, Hôpitaux de Paris, Hôpital Saint-Antoine, Service de Réanimation Médicale, Paris 75012, France ${ }^{8}$ Department of Intensive Care Medicine, University Medical Center, University of Utrecht, Utrecht, Netherlands
\end{abstract}

\section{Correspondence to}

Professor Hans Flaatten, Department of Anaesthesia, Haukeland Universitetssjukehus, Bergen, Norway;

hans.flaatten@uib.no

Received 22 May 2020 Accepted 31 May 2020

\section{Check for updates}

(C) Author(s) (or their employer(s)) 2020. Re-use permitted under CC BY-NC. No commercial re-use. See rights and permissions. Published by BMJ.

To cite: Flaatten $\mathrm{H}$, Van Heerden $V$, Jung $C$, et al. $J$ Med Ethics Epub ahead of print: [please include Day

Month Year]. doi:10.1136/

medethics-2020-106489

\section{ABSTRACT}

In this analysis we discuss the change in criteria for triage of patients during three different phases of a pandemic like COVID-19, seen from the critical care point of view. Availability of critical care beds has become a hot topic, and in many countries, we have seen a huge increase in the provision of temporary intensive care bed capacity. However, there is a limit where the hospitals may run out of resources to provide critical care, which is heavily dependent on trained staff, just-in-time supply chains for clinical consumables and drugs and advanced equipment. In the first (good) phase, we can still do clinical prioritisation and decision-making as usual, based on the need for intensive care and prognostication: what are the odds for a good result with regard to survival and quality of life. In the next (bad phase), the resources are mostly available, but the system is stressed by many patients arriving over a short time period and auxiliary beds in different places in the hospital being used. We may have to abandon admittance of patients with doubtful prognosis. In the last (ugly) phase, usual medical triage and priority setting may not be sufficient to decrease inflow and there may not be enough intensive care unit beds available. In this phase different criteria must be applied using a utilitarian approach for triage. We argue that this is an important transition where society, and not physicians, must provide guidance to support triage that is no longer based on medical priorities alone.

The present SARS-CoV-2 pandemic has fuelled academic and public discussions regarding the prospects and limitations of treatment in critically ill patients. ${ }^{1}$ Newspapers and television shows are debating the consequences of triage decisions of policymakers and physicians. While decisionmaking on individual patients belongs to the core competencies of physicians, being challenged by the public on the societal consequences is new for most. Facing an enormous influx of critically ill patients with a new corona virus disease, we as intensive care physicians were forced to prepare for the worst-what if we no longer have the capacity to care for all patients presenting to us? What if we had to choose between two patients and only have one ventilator? Here we discuss the good, the bad and the ugly of decision-making in critical care during the COVID-19 pandemic.

Usually we decide, together with the patient, if a treatment is proportional to the expected outcome and the potential suffering that is imposed on the patient. This shared decision-making is particularly difficult when the condition is emergent and critical and the patient's prospect to return to his/her baseline is uncertain, for example in people with frailty and serious comorbidities. When considering intensive care unit (ICU) admission, the objective is always to identify patients who will benefit from the expensive and stressful interventions in intensive care. However, such decisions are almost exclusively made in 'the midst of plenty'. In Europe we have a reasonable number of ICU beds, especially compared with many places in the world, although the number of beds in relation to the number of inhabitants varies. ${ }^{2}$

One of the biggest challenges in decision-making is whether (or not) to admit the very elderly patients ( $\geq 80$ years) to intensive care. The proportion of elderly patients in the ICU is steadily increasing and may well reach 'pandemic' proportions in many parts of the world. This has prompted a focus on this challenge in order to explore who will benefit from intensive care, and prognostication in this group of patients . ${ }^{34}$ These elderly patients are most susceptible to SARS-CoV-2 virus and mortality of COVID-19 is particularly high in elderly patients. ${ }^{5}$ Many guidelines dealing with the admission and triage of COVID-19 patients struggle with which criteria for elderly patients should be utilised. Some choices are based on good quality medical evidence ('the good') but some choices have to be made out of scarcity ('the ugly', figure 1). Here we will discuss enforced criteria that have been proposed for times of major stress to the hospital system in the present pandemic, and lastly another way to handle triage that in our opinion leaves the medical field and enters the arena of politics and society as a whole.

\section{THE GOOD}

The question that we should always be asking ourselves is: What is best for the patient? This question should be patient-centred and be independent on resources or economics. While cost-effectiveness discussions are important for healthcare in general they should not be part of the considerations in individual patient care: 'Sorry, your budget is spent'. On reviewing a patient for ICU admission, you have to decide whether an elderly patient should be admitted and endure demanding treatment regimens. Prognostication is important. What are the odds of a good result, survival with as little loss of quality of life (QOL) as possible, or a bad result, death or severe disability? These are important questions and currently we have good quality evidence to support our decision-making. In the very old patients in ICU, it is quite clear that the pre-ICU level and trajectory of frailty, activities of daily life and cognition play a major role. 


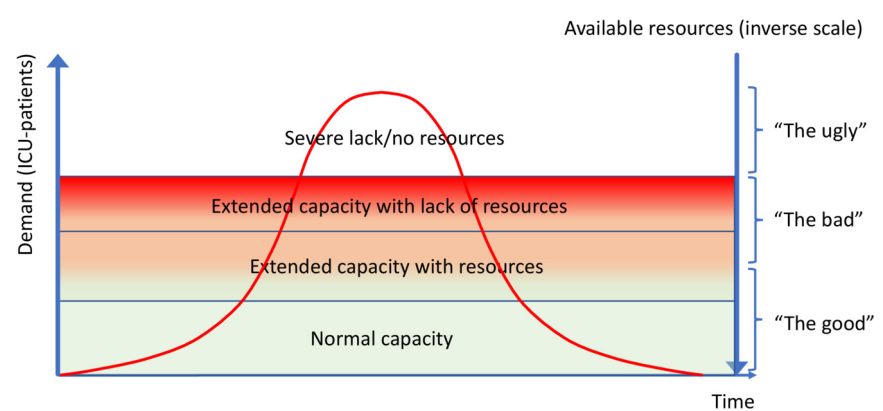

Figure 1 This figure illustrates in general the relation between demand and resources during a pandemic in a simplistic way, and the zones: good, bad and ugly.

Particularly when we look beyond ICU survival these premorbid functional capacities are strong predictors of patient-centred outcome measures such as QoL and independent physical functioning. ${ }^{6}$ Therefore, it is quite understandable that premorbid function has become an important determinant in COVID-19 triage protocols, but in some countries use of the Clinical Frailty Scale has been restricted to patients over 65 years of age. ${ }^{7}$ In addition, the severity of the acute illness is obviously important with regard to short-term outcome such as ICU and hospital survival. In an elderly patient with a high degree of disability and frailty combined with extensive organ dysfunction, the odds are very small with regard to both survival and preserved QoL in survivors. It is important to note, though, that these predictors are derived from group-based statistics and prognostication for the individual remains inherently uncertain. There is no 87 year old with 'average' multimorbidity. Even the level of expertise of the treating physician involved in this process does not change this fundamental problem. ${ }^{8}$ However, the available intensive care capacity during 'good' times provides the opportunity to admit patients for a time-limited trial and assess their critical illness and response to treatment over time.

\section{THE BAD}

The fundamentals of triage and prognostication described in the prior section may be challenged and modified in a situation where there are many patients arriving in a critical condition at the same time (the orange zone in figure 1). In order to maintain the structure and quality of intensive care provision, we need to be more restrictive in our admission criteria to prevent ICU resources from becoming overwhelmed. ${ }^{9}$ There are multiple reasons for this, ICU staff stress, potential shortage of certain vital resources such as ICU beds staffed with experienced specialists, and expansion into other areas like postoperative units with consequences for scheduled major surgery. In this phase the major task is to provide sufficiently resourced ICU beds which comply with an acceptable standard of care. The 'luxury' of admitting patients with doubtful prognosis, however, might be lost with admission criteria solely based on models derived from group statistics. It is, thus, inevitable, that members of the heterogeneous cohort of very elderly miss their chance. ${ }^{10}$ During this phase of surge capacity normal care will be diminished to a level that only very ill patients will be admitted, and with a lack of public/official guidelines many hospitals will be forced to write local triage protocols. ${ }^{1}$ Most elective care will be postponed until better times. Without a doubt some patients will deteriorate during this time and their chances for a good outcome will be reduced in comparison to the prepandemic era.

\section{THE UGLY}

If the demand for intensive care exceeds the supply of resources (red zone), usual medical triage and priority setting are not sufficient to decrease the inflow of patients into intensive care. If capacity is available with some rudimentary equipments, we may try to keep it going for a limited period before we enter the white zone, where resources run out (figure 1). At this point we are no longer able to provide intensive care even of a questionable quality to all. This means that new patients will only be given intensive care when and if a bed becomes available again, and the hospital has to consider other ways of allocating the resource, one of which may be the principle of 'first come, first served'. The best that can be said about this unplanned triage is that it is completely arbitrary, like winning a lottery where you receive only one ticket, and as such the principle is fair; all patients will in theory have an equal chance to receive treatment. This is the extreme end of the egalitarian approach to distributive justice where all are treated equally, in contrast to a utilitarian approach where individuals are weighted differently according to their contribution to the overall good for the society. There are indications that COVID-19 may force healthcare in this direction in some countries. ${ }^{112}$

We know little about what the society would want us to do under such extreme conditions. In a study from Maryland, USA, forums of general public and healthcare professionals discussed ethical guidelines during a catastrophe with severe limitation of resources. ${ }^{13}$ They found that the majority of participants gave priority to saving the most lives and saving the most life-years and gave low priority to the principle of first come, first served. With this exception, very little is known about the attitude of the general public in such matters.

One way to prioritise saving lives and life-years is to set an absolute age limit to gain access to intensive care. This was in fact proposed both in Italy and Spain during the peak of the pandemic, ${ }^{114}$ and depending on where the age-threshold is setting this approach may reduce the number of patients dramatically. As documented above, some may judge such triage as fair, since the old have lived their life, or at least most of it, while the young may have more than half of their expected lifetime ahead in addition to an increased chance of survival. For society this will 'produce' more survivors in the short term that may also contribute for longer to society after the pandemic. However, the longer-term impact of this utilitarian approach on societal values in many countries remains to be elucidated. Whether the priority discussion should also include patients already receiving ICU treatment, such as ventilation, has been discussed, with the overall aim to saving lives and life-years. Interestingly $58 \%$ of lay participants and $79 \%$ of healthcare workers in this study answered yes to a direct question of whether to remove a ventilator and give it to another patient. ${ }^{13}$ There are also more difficult questions. When deciding between two medically similar patients, should we prioritise those caring for small children or those with specific professions such as nurses and doctors?, ${ }^{14}$ the latter is important in order to maximise the hospital staff for the coming weeks and months. Most of us would certainly consider such triage criteria as non-medical, and hence should not be performed by the medical staff but left to society to decide who should make this decision.

It is important to have agreement that we as physicians must perform priority and triage on purely medical grounds, accepting that all humans have an equal right to be treated if they are critically ill. This demands that the professional societies discuss these issues upfront, in collaboration with the public, and 
are open about the principles they would want us to follow, both in times when resources are available, but in particular when we run out of reserves. The public also needs education about what critical care can do and what we can-not, in order to deal with unrealistic expectations within the population.

The 'ugly' scenario may appear very unlikely to most of us, but it is not impossible. The present pandemic has already challenged us and we have stared the ugly scenario in the face. We must accept that resources are not unlimited, even in our part of the world. We need a clear and open discussion about where the borders are for the medical profession to perform triage 'beyond' what is accepted within medical ethics and also where the responsibility of society and government lie. The government and society need to urgently discuss and even codify the concept of triage being a necessity. In the event that resources are overwhelmed, be it by the wave of elderly patients presenting to the ICU or during a pandemic, it is unreasonable to expect already hard worked healthcare workers to make difficult and impossible decisions in a high-pressured environment. We have already seen the warning signs, let us discuss this now and come to some decisions, be they good, bad or ugly.

Contributors All authors share the idea of the manuscript, HF drafted the manuscript and all coauthors participated in discussion and editing.

Funding The authors have not declared a specific grant for this research from any funding agency in the public, commercial or not-for-profit sectors.

Competing interests None declared.

Patient consent for publication Not required.

Provenance and peer review Not commissioned; internally peer reviewed.

Open access This is an open access article distributed in accordance with the Creative Commons Attribution Non Commercial (CC BY-NC 4.0) license, which permits others to distribute, remix, adapt, build upon this work non-commercially, and license their derivative works on different terms, provided the original work is properly cited, appropriate credit is given, any changes made indicated, and the use is non-commercial. See: http://creativecommons.org/licenses/by-nc/4.0/.

\section{REFERENCES}

1 Herreros B, Gella P, Real de Asua D, de Asua Diego R. Triage during the COVID-19 epidemic in Spain: better and worse ethical arguments. J Med Ethics 2020;0:medethics-2020-106352-4.

2 Rhodes A, Ferdinande P, Flaatten $\mathrm{H}$, et al. The variability of critical care bed numbers in Europe. Intensive Care Med 2012:38(10):1647-53.

3 Flaatten $\mathrm{H}$, de Lange DW, Artigas A, et al. The status of intensive care medicine research and a future agenda for very old patients in the ICU. Intensive Care Med 2017:43(9):1319-28.

4 de Lange DW, Brinkman S, Flaatten $\mathrm{H}$, et al. Cumulative prognostic score predicting mortality in patients older than 80 years admitted to the ICU. J Am Geriatr Soc 2019:67(6):1263-7.

5 ICNARC report on COVID-19 in critical care 15 may 2020. Available: https://www. icnarc.org/Our-Audit/Audits/Cmp/Reports [Accessed May 2020].

6 Guidet B, de Lange DW, Boumendil A, et al. The contribution of frailty, cognition, activity of daily life and comorbidities on outcome in acutely admitted patients over 80 years in European ICUs: the VIP2 study. Intensive Care Med 2020;46(1):57-69.

7 National Institute for health and Care Excellence. COVID-19 rapid guideline: critical care in adults, 2020. Available: https://www.nice.org.uk/guidance/ng159/resources/ critical-care-admission-algorithm-pdf-8708948893 [Accessed May 2020].

8 Meadow W, Pohlman A, Frain L, et al. Power and limitations of daily prognostications of death in the medical intensive care unit. Crit Care Med 2011:39(3):474-9.

9 Pagel C, Utley M, Ray S. COVID-19: how to triage effectively in a pandemic. The BMJ opinion, 2020. Available: https://blogs.bmj.com/bmj/2020/03/09/covid-19-triage-in-a pandemic-is-even-thornier-than-you-might-think/ [Accessed May 2020].

10 Sprung $C L$, Baras $M$, lapichino $G$, et al. The Eldicus prospective, observational study of triage decision making in European intensive care units: part I--European Intensive Care Admission Triage Scores. Crit Care Med 2012;40(1):125-31.

11 Germain S. Will COVID-19 mark the end of an egalitarian National health service? Eur J Risk Regul 2020:9:1-8.

12 Emanuel EJ, Persad G, Upshur R, et al. Fair allocation of scarce medical resources in the time of Covid-19. N Engl J Med 2020;382(21):2049-55.

13 Biddison ELD, Gwon HS, Schoch-Spana M, et al. Scarce resource allocation during disasters: a Mixed-Method community engagement study. Chest 2018;153(1):187-95.

14 Mannelli C. Whose life to save? scarce resources allocation in the COVID-19 outbreak. $J$ Med Ethics 2020;46(6):364-6. 